Research Article

\title{
Optimal Insurance Indemnity and Reinsurance Strategy for Health Insurance
}

\author{
Yan Zhang $\mathbb{D},{ }^{1,2}$ Yonghong $\mathrm{Wu} \mathbb{D},{ }^{3}$ and Haixiang Yao $\mathbb{i D}^{2}$ \\ ${ }^{1}$ Southern China Institute of Fortune Management Research (IFMR), Guangdong University of Foreign Studies, \\ Guangzhou 510006, China \\ ${ }^{2}$ School of Finance, Guangdong University of Foreign Studies, Guangzhou 510006, China \\ ${ }^{3}$ Department of Mathematics and Statistics, Curtin University, WA 6845, Australia \\ Correspondence should be addressed to Yan Zhang; chang.agatha@yahoo.com
}

Received 18 May 2021; Revised 29 June 2021; Accepted 4 August 2021; Published 14 August 2021

Academic Editor: Emilio Gómez-Déniz

Copyright (C) 2021 Yan Zhang et al. This is an open access article distributed under the Creative Commons Attribution License, which permits unrestricted use, distribution, and reproduction in any medium, provided the original work is properly cited.

\begin{abstract}
"Health insurance + health management" package has recently become one of the most important nonlife insurance products, and its pricing technique has drawn attention from both academia and industry. This paper investigates the optimal indemnity design and per-loss reinsurance strategy for the health insurance package, where the reinsurance contract is assumed to combine the quota-share type and the excess-of-loss type. By applying the Lagrange multiplier method and optimal control technique, we develop the solutions to the corresponding optimization problems and obtain the optimal deductible. Then, we proceed to solve the optimal quota-share proportion and the optimal stop-loss retention based on the optimal insurance indemnity. In addition to theoretical results, numerical examples are also given to illustrate the effects of various key parameters on the optimal indemnity design and combinational reinsurance strategy.
\end{abstract}

\section{Introduction}

For an individual or a group, insurance is one of the most important risk management strategies by transferring risk from the insured to the insurer. In order to balance the competitiveness and profitability of insurance products, pricing and indemnity design are the essential work that concerns both actuaries and researchers. The authors in [1-3] established the optimal insurance framework under static setting and showed that the deductible insurance is optimal in the sense of maximizing the expected concave utility function of an insurer's wealth. Since then, various models on optimal insurance design have been formulated and studied extensively, for instance, modeks of Smith [4], Spence and Zeckhauser [5], Raviv [6], Gollier and Schlesinger [7], Young [8], Wang et al. [9], Promislow and Young [10], Moore and Young [11], Lee [12], Zhou and $\mathrm{Wu}$ [13], and references therein. More recently, Zhou et al. [14] developed an optimal insurance in the presence of insurer's loss limit and proved that the optimal insurance is an inferior (normal) good for the insured with a DARA (IARA) utility function. Bernard et al. [15] studied an optimal insurance design problem under the rank-dependent expected utility with a concave utility function and an inverse-S shaped probability distortion function. $\mathrm{Xu}$ et al. [16] investigated an optimal insurance design problem under rankdependent utility and incentive compatibility. We notice that the evolution of insured's utility plays a leading role in this research field, since the solution to the corresponding optimization problem depends on the assumption of the insured's preference.

In order to formulate the utility function for health insurance problem, we investigate the relevant literatures. As people's attention on health has stimulated the demand for healthcare services, many research articles on relevant topics have been contributed into literature, for example, works of Sarkar and Sana [17, 18], Modak et al. [19], and Moheimani et al. $[20,21]$. In the field of health insurance, the existing literature can be classified into two categories: (1) research on demand and effect of health insurance and (2) research 
on utility of health and wealth and pricing of health insurance based on utilty. In the first category, classical articles are included but not limited to works of Besley [22], Ellis et al. [23], Bhargava et al. [24], and Doiron and Kettlewell [25]. In the second category, many scholars have studied the formulation of utility functions and efficient health insurance by both theoretical and empirical analysis. Viscussi and Evans [26] studied the health state-dependent utility functions that describe job injury and impact on income. Blomqvist [27] derived the optimal nonlinear health insurance via dynamic optimization techniques and analyzed its properties. Hall and Jones [28] investigated the relations between the growth of health spending and the economic conditions. Finkelstein et al. [29] discussed the effect of health on the marginal utility of consumption. Zhang and $\mathrm{Wu}$ [30] proposed the optimal health insurance indemnity design under utility of health and wealth. Inspired by Viscussi and Evans [26], Lee [12], Levy and Nir [31], and Pliskin et al. [32], as elaborated in Zhang et al. [33], we use the utility of health, wealth, and incomes to describe the insured's preference in this paper and derive the optimal insurance indemnity accordingly.

In addition to optimizing the indemnity design, the insurer should also consider risk management strategy. By transferring risk from the insurer to the reinsurer, reinsurance is a powerful tool for risk management. Therefore, the optimal reinsurance problem has become a popular research topic in both academia and industry for decades. Most of the research articles on reinsurance can be classified into one of the following two types. The first type is on the design of optimal proportional or excess-of-loss reinsurance under various constraints. Recent references include Cai and Tan [34], Tan et al. [35], Yusong and Jin [36], Chi and Tan [37], Cai et al. [38, 39], Zhang et al. [40], Liang and Young [41], Han et al. [42], Fang et al. [43], and the references therein. The second type is on the design of optimal combinational proportional and excess-of-loss reinsurance under different optimization criteria. A few attempts have been made on model formulation and solution scheme of combinational reinsurance, for example, Zhang et al. [44] investigated the optimal combinational quota-share and excess-of-loss reinsurance problem in a dynamic setting. Liang and Guo [45] studied the optimal quota-share and excess-of-loss reinsurance to maximize the insurer's expected exponential utility. Fang and $\mathrm{Qu}$ [46] derived the optimal combinational quota-share and stop-loss reinsurance under the optimization criterion of maximizing the insurer-reinsurer joint survival probability. More recent literature on combinational reinsurance can be found in the works of Hu et al. [47], Yang et al. [48], and Christian [49]. Compared with single type of reinsurance treaty, the combinational reinsurance strategy is more realistic. As proposed in Mcguire et al. [50], the application of reinsurance in health insurance at the individual level can yield substantial improvements in fit of payments to health plan spending, by using data from Germany, the Netherlands, and the US marketplaces. As far as we know, the optimal insurance-combinational reinsurance design problem for health insurance has not been addressed completely.
Inspired by Mcguire et al. [50] and the aforementioned reinsurance literature, we devote this paper to the study of optimal insurance-reinsurance problem in health plan at the individual level.

In this paper, we consider the optimal insurance indemnity and combinational reinsurance strategy for "health insurance + health management" packages. In addition to indemnity, based on diagnosis or treatment cost, the insured is provided with health advice and discounted premium under certain conditions. We refer the readers to Zhang and $\mathrm{Wu}$ [30] and Zhang et al. [33], for more details of the model setup. Three parties, i.e., the insured, the insurer, and the reinsurer, are considered in this paper. The optimal insurance indemnity design is obtained by maximizing the insured's expected utility; the optimal reinsurance treaties that combine both the quota-share type and the excess-of-loss type are solved under the optimization criterion of minimizing value-at-risk (VaR) of truncated medical cost. Therefore, we have to solve two optimization problems in sequence.

To the best of our knowledge, our paper is the first attempt to solve the optimal insurance-reinsurance problem for the design of health plans at the individual level and is the first article that investigates both pricing and risk management for health insurance products. The main contribution of this article is threefold. (1) We extend the work of Zhang et al. [33] to take into account the health management option in the sense of maximizing insured's expected utility. (2) We combine the quota-share reinsurance and the excessof-loss reinsurance and design the optimal treaty. (3) We compare the quota-share reinsurance with the excess-of-loss reinsurance under the established optimal deductible.

The Lagrange multiplier method, the optimal control technique, and the static optimization technique are applied in this paper. To solve the optimal insurance-reinsurance problem for health insurance, we formulate the problem into two optimization problems in sequence, i.e., the optimal insurance problem and the optimal reinsurance problem based on the optimal insurance indemnity. A numerical algorithm is then developed to solve the optimization problems in three steps: firstly, we apply the Lagrange multiplier method to transfer the constrained optimization problem to unconstrained optimization problem; secondly, we apply the optimal control technique to solve the unconstrained optimization problem; finally, we proceed to determine the global optimal solution via a static optimization technique. The Hamiltonian function and the inequalities are constructed or adjusted according to the model formulation.

The remainder of this paper is organized as follows. Section 2 describes the model for the health insurance problem and then constructs two optimization problems, with one for insurance indemnity design and the other one for combinational reinsurance strategy. In Section 3, by the Lagrange multiplier method, optimal control technique, and static optimization technique, we derive the optimal deductible, the optimal optimal quota-share proportion, and the optimal stop-loss retention, respectively. Section 4 gives numerical examples to show the effects of various key 
parameters on the optimal insurance-reinsurance treaties. We conclude this paper in Section 5.

\section{Problem Formulation}

In this section, we present the "health insurance + health management" package in the sense that the insured's utility varies under different situations. Then, we formulate the optimal insurance indemnity design problem for the insured who is offered the "health insurance + health management" package. With the optimal deductible in force, we then further formulate the optimal combinational reinsurance treaty problem for the insurer to minimize the $\mathrm{VaR}$ of truncated loss, under the reinsurance premium constraint.

2.1. The "Health Insurance + Health Management" Package. To measure the effect of health management on optimal insurance indemnity, we utilize different mathematical models to describe the insured's utility under various situations. As in Zhang et al. [33], we use the utility of health, wealth, and income in this study:

$$
\begin{aligned}
U(h, w, y) & =h \cdot U(w, y) \\
& =h \cdot(U(y)+\delta V(w)) \\
& =h \cdot(\log (y)+\delta \log (w)),
\end{aligned}
$$

where $0 \leq h \leq 1$, with 0 representing death and 1 representing perfect health, $w>0$ and $y>0$ denote, respectively, the wealth and income, and $\delta$ is a discount factor or weighting factor. Suppose that the insured has initial health status $h_{0}$, initial wealth $w_{0}$, and income $y_{0}$, with no shocks to health status occurring; then, his/her utility is

$$
\begin{aligned}
U\left(h_{0}, w_{0}, y_{0}-\text { premium }\right)= & h_{0} \cdot\left(\log \left(y_{0}-\text { premium }\right)\right. \\
& \left.+\delta \log \left(w_{0}\right)\right) .
\end{aligned}
$$

During the term of the health insurance, the insured is provided with health management service and the insurance company can continuously collect data from the insured's daily behavior. If the insured follows health management advice and lives a healthy life style, his/her health status may get improved. In this case, the insurer may offer a discount premium to the insured. Therefore, the utility of the insured is

$$
U\left(h_{1}, w_{1}, y_{1}\right)=h_{1} \cdot\left(\log \left(y_{0}-\alpha \cdot \operatorname{premium}\right)+\delta \log \left(w_{0}\right)\right),
$$

where $h_{1}$, satisfying $h_{0} \leq h_{1} \leq 1$, is the improved health status and $\alpha, 0<\alpha<1$, is a prespecified discount rate of premium. If the insured gets mild disease or severe illness, he/she will take medical treatment in hospital and get reimbursement for the cost and related loss from the insurer. However, the indemnity could help the insured rescue from disastrous financial burden, but it may still yield a lower utility of health. To summarize, the insured's health status might be the same as the last year or get deteriorated. Therefore, the utility of the insured is

$$
\begin{aligned}
U\left(h_{2}, w_{2}, y_{2}\right)= & h_{2} \cdot\left(\log \left(y_{0}-\text { premium }\right)\right. \\
& +\delta \log \left(w_{0}-\text { loss }+ \text { indemnity }\right),
\end{aligned}
$$

where $h_{2}$, satisfying $0 \leq h_{2} \leq h_{0}$, is the adjusted health status and $w_{2}>0$ is the adjusted wealth.

2.2. The Optimal Insurance Indemnity Design Problem. Suppose the insured, with initial health status $h_{0}$, initial wealth $w_{0}$, and income $y_{0}$, faces exogenous shocks to health status which would incur a positive continuous random financial loss $X$ defined on the probability space $(\Omega, \mathscr{F}, \mathbb{P})$. The insured purchases health insurance against the loss $X$ by paying a nonnegative premium $\pi$ to the insurer in return for a so-called indemnity $I(X)$, which satisfies the conditions $I(0)=0,0 \leq I(x) \leq x, \forall x \geq 0$. In the following, we denote by $\mathscr{I}$ the set of all indemnity functions which satisfy the conditions. We assume that each individual is restricted to being covered by a single plan and receive "necessary" health service if he/she is sick or injured. According to Arrow [2] and Raviv [6], for a risk-neutral insurer, if the cost of offering the insurance is proportional to the expected value of the indemnity $E[I(X)]$, then the insurer requires $(1+\rho) E[I(X)] \leq \pi$, where $\rho \geq 0$ denotes the loading factor.

In the case that the insured's state shifts from "healthy" to "sick" during the period covered by the insurance, then his/her health status decreases from $h_{0}$ to $h_{0}-\theta$, where $\theta$ is a measure of the difference between the original health status before shocks occur and the health status after medical treatment ends. We assume that $\Theta$ is a discrete random variable and takes value in $\left[\theta_{l}, \theta_{u}\right]$, where $0 \leq \theta_{l}<\theta_{u}<h_{0}$, with 0 indicating that the insured fully recovers from treatment. For convenience, we assume the probability that no shock to insured's health status occurs is $p_{0}$; the probability that the insured improves health status is $p_{1}$. For the case in which shocks to the insured's health status occur, we define the related probabilities as follows:

$$
\begin{aligned}
p_{\theta_{i}} & =\operatorname{Prob}\left[\Theta=\theta_{i}\right], \\
p_{2} & =\sum_{\theta_{i} \in\left[\theta_{l}, \theta_{u}\right]} p_{\theta i}, \\
p_{0}+p_{1}+p_{2} & =1 .
\end{aligned}
$$


Then, from equations (2) to (4), the insured's expected utility under application of health management can be calculated as follows:

$$
\begin{aligned}
E[U & (X, \Theta, I(X), \pi)] \\
\equiv & p_{0} h_{0} \cdot\left(\log \left(y_{0}-\pi\right)+\delta \log \left(w_{0}\right)\right) \\
& +p_{1} h_{1} \cdot\left(\log \left(y_{0}-\alpha \cdot \pi\right)+\delta \log \left(w_{0}\right)\right) \\
& +\sum_{\theta_{i} \in\left[\theta_{l}, \theta_{u}\right]} p_{\theta i} \int_{0}^{\infty}\left(h_{0}-\theta_{i}\right) \cdot\left(\log \left(y_{0}-\pi\right)+\delta \log \left(w_{0}-x+I(x)\right)\right) \mathrm{d} F\left(x \mid \Theta=\theta_{i}\right),
\end{aligned}
$$

where $F\left(x \mid \Theta=\theta_{i}\right)$ is the conditional distribution of $X$ given $\left(\Theta=\theta_{i}\right)$, provided that shocks to the insured's health status occur.

The risk-averse insured aims to maximize the expected utility against unpredictable shocks to health status. With the indemnity function $I(X) \in \mathscr{I}$ as the decision variable, the optimal health insurance model can be formalized as follows.

Problem P1:

$$
\begin{aligned}
& \text { Maximize } E[U(X, \Theta, I(X), \pi)] \\
& \text { subject to } p i \geq(1+\rho) E[I(X)] .
\end{aligned}
$$

2.3. The Optimal Combinational Reinsurance Strategy Problem. With the optimal indemnity $I^{*}\left(x, \pi^{*}\right)$ in force, let $Y$ denote the claim borne by the insurer before reinsurance arrangement, with distribution function $F_{Y}(y)$ and probability density function $f_{Y}(y)$. Throughout the paper, we define $(x)^{+}=\max \{x, 0\}$ and $x \wedge y=\min \{x, y\}$. In what follows, we assume that the insurer arranges a combination of quota-share and excess-of-loss reinsurance in the way of Zhang et al. [44], Fang and Qu [46], and Yang et al. [48]:

(1) Firstly, the insurer arranges a quota-share reinsurance treaty with the retention level $a, 0 \leq a \leq 1$ so that the claim covered by the insurer becomes $a Y$.

(2) Secondly, the insurer arranges a excess-of-loss reinsurance treaty with the retention level $b, 0 \leq b<+$ $\infty$ so that the claim covered by the insurer is $\min \{a Y, b\}=a Y \wedge b$.

(3) As such, the claim covered by the reinsurer is $Y-a Y \wedge b$.

(4) In return, the insurer has to pay for reinsurance premium based on the expected value principle, i.e., $(1+\eta) E[Y-a Y \wedge b]$, where $\eta>0$ is the safety loading of the reinsurer. Without loss of generality, we assume that $\eta>\rho$, which means that the insurer cannot reinsure the whole risk with a certain profit.

(5) To ensure the net premium received by the insurer after reinsurance is positive, we impose the constraint $E[Y-a Y \wedge b] \leq\left(\beta \pi^{*} /(1+\eta)\right)$ on reinsurance treaty, where $\beta \pi^{*}$ with $0<\beta<1$ is the maximum reinsurance premium that can be accepted by the insurer.
Let $\mathcal{U}$ denote the set of all admissible combinational quota-share and excess-of-loss reinsurance retentions $(a, b)$ which satisfy the aforementioned conditions. The insurer aims to minimize the $\mathrm{VaR}$ of the borne risk at a confidence level $p$.

Definition 1. The value-at-risk at the confidence level $p(0<p<1)$, for a nonnegative random variable $X$ with distribution function $F(x)$, denoted by $\operatorname{VaR}_{p}(X)$, is defined as

$$
\begin{aligned}
\operatorname{VaR}_{p}(X) & =\inf \{x \in \mathscr{R}: F(x) \geq p\}=F^{-1}(p), \\
\operatorname{Prob}\left[X \leq \operatorname{VaR}_{p}(X)\right] & =p .
\end{aligned}
$$

Proposition 1. In [51], for two random losses $X$ and $Y$, the $V a R$ risk measure satisfies the following properties:

(1) Translation invariance: $\operatorname{VaR}_{p}(X+c)=\operatorname{VaR}_{p}(X)+c$

(2) Positive homogeneity: $\operatorname{VaR}_{p}(c X)=c \operatorname{VaR}_{p}(X)$

(3) Monotonicity: $\operatorname{VaR}_{p}(X) \leq \operatorname{VaR}_{p}(Y)$ if $\operatorname{Prob}(X \leq$ $Y)=1$

With $(a, b) \in \mathcal{U}$ as the decision variables, the optimal reinsurance strategy problem can be described as follows.

Problem P2:

$$
\begin{aligned}
& \text { Minimize } \operatorname{VaR}_{p}[a Y \wedge b] \\
& \text { subject to } E[Y-a Y \wedge b] \leq \frac{\beta \pi^{*}}{1+\eta} \text {. }
\end{aligned}
$$

Remark 1. The insurance premium $\pi^{*}$, in the constraint of the optimization Problem $\mathbf{P}_{2}$, is obtained in the solution to the optimization Problem $\mathbf{P}_{1}$.

Remark 2. The formulation and solution of the Mean-VaR combinational reinsurance optimization problem for excessof-loss before quota-share is given in Appendix.

\section{Solution Scheme}

In this section, we firstly apply the Lagrange multiplier method and optimal control technique to obtain the optimal insurance indemnity by solving the optimization problem 
$\mathbf{P}_{1}$. Then, we utilize $\mathrm{VaR}$ as the optimization criterion to derive the optimal combinational quota-share and excess-ofloss reinsurance strategy based on the optimal deductible and the optimal insurance premium.

3.1. The Optimal Insurance Indemnity. We derive the solution to problem $\mathbf{P}_{1}$ in two steps as detailed below.
Proposition 2. The solution to the optimization problem $\mathbf{P}_{1}$, for a fixed premium $\pi$, is

$$
\begin{aligned}
I^{*}(x) & =(x-d)^{+}, \\
d & =w_{0}-\frac{\sum_{\theta_{i} \in\left[\theta_{l}, \theta_{u}\right]} p_{\theta i}\left(h_{0}-\theta_{i}\right) \delta f\left(x \mid \Theta=\theta_{i}\right)}{\lambda(1+\rho) \sum_{\theta_{i} \in\left[\theta_{l}, \theta_{u}\right]} p_{\theta_{i}} f\left(x \mid \Theta=\theta_{i}\right)},
\end{aligned}
$$

where $d$ is a nonnegative deductible and satisfies

$$
(1+\rho) E[I(X)]=(1+\rho) \sum_{\theta_{i} \in\left[\theta_{l}, \theta_{u}\right]} p_{\theta_{i}} \int_{0}^{\infty} I^{*}(x) \mathrm{d} F\left(x \mid \Theta=\theta_{i}\right)=\pi
$$

Proof. $I(x)$ is written by $I$ for notational simplicity. Let

$$
\begin{aligned}
L= & \sum_{\theta_{i} \in\left[\theta_{l}, \theta_{u}\right]} p_{\theta i} \int_{0}^{\infty}\left(h_{0}-\theta_{i}\right) \cdot\left(\log \left(y_{0}-\pi\right)+\delta \log \left(w_{0}-x+I\right)\right) \mathrm{d} F\left(x \mid \Theta=\theta_{i}\right) \\
& -\lambda\left((1+\rho) \sum_{\theta_{i} \in\left[\theta_{l}, \theta_{u}\right]} p_{\theta_{i}} \int_{0}^{\infty} I \mathrm{~d} F\left(x \mid \Theta=\theta_{i}\right)-\pi\right),
\end{aligned}
$$

where $\lambda$ is the Lagrange multiplier. The Hamiltonian function is

$$
\begin{aligned}
H= & \sum_{\theta_{i} \in\left[\theta_{l}, \theta_{u}\right]} p_{\theta i}\left(h_{0}-\theta_{i}\right) \cdot\left(\log \left(y_{0}-\pi\right)+\delta \log \left(w_{0}-x+I\right)\right) f\left(x \mid \Theta=\theta_{i}\right) \\
& -\lambda(1+\rho) \sum_{\theta_{i} \in\left[\theta_{l}, \theta_{u}\right]} p_{\theta_{i}} \operatorname{If}\left(x \mid \Theta=\theta_{i}\right) .
\end{aligned}
$$

Step 1 : ee keep the insurance premium $\pi$ fixed and solve for the optimal health insurance indemnity $I^{*}(x, \pi)$. Assuming that $w_{0} \geq\left(\left(\sum_{\theta_{i}}\right.\right.$ $\left.\in\left[\theta_{l}, \theta_{u}\right] p_{\theta i}\left(h_{0}-\theta_{i}\right) \quad \delta f\left(x \mid \Theta=\theta_{i}\right)\right) /(\lambda$ $\left.\left.(1+\rho) \sum_{\theta_{i} \in\left[\theta_{l}, \theta_{u}\right]} p_{\theta_{i}} f\left(x \mid \Theta=\theta_{i}\right)\right)\right)$, we establish and prove the following proposition.

The Hamiltonian function is concave in $I$. From the first-order condition $(\partial H / \partial I)=0$, we have

$$
\begin{gathered}
\sum_{\theta_{i} \in\left[\theta_{l}, \theta_{u}\right]} p_{\theta i}\left(h_{0}-\theta_{i}\right) f\left(x \mid \Theta=\theta_{i}\right) \frac{\delta}{w_{0}-x+I} \\
=\lambda(1+\rho) \sum_{\theta_{i} \in\left[\theta_{l}, \theta_{u}\right]} p_{\theta_{i}} f\left(x \mid \Theta=\theta_{i}\right) .
\end{gathered}
$$

Solving (14), we obtain the following optimal solution under fixed premium $\pi$ :

$$
\begin{aligned}
I^{*}(x) & =(x-d)^{+}, \\
d & =w_{0}-\frac{\sum_{\theta_{i} \in\left[\theta_{l}, \theta_{u}\right]} p_{\theta i}\left(h_{0}-\theta_{i}\right) \delta f\left(x \mid \Theta=\theta_{i}\right)}{\lambda(1+\rho) \sum_{\theta_{i} \in\left[\theta_{l}, \theta_{u}\right]} p_{\theta_{i}} f\left(x \mid \Theta=\theta_{i}\right)},
\end{aligned}
$$

where $d$ is a nonnegative deductible and satisfies $(1+\rho) E\left[(x-d)^{+}\right]=\pi$. Thus, we have proved the proposition.

Step 2 : we proceed to determine the global optimal insurance indemnity $I^{*}\left(x, \pi^{*}\right)$. The result is summarized in the following proposition.

Proposition 3. If $I^{*}(x)$, the optimal solution to the optimization problem $\mathbf{P}_{1}$, is a deductible insurance in the form of (15), then $I^{*}(x)$ should satisfy the following equation: 


$$
\begin{aligned}
0= & \mathscr{K} \frac{p_{0} h_{0}}{y_{0}-(1+\rho) E\left[I^{*}\right]}+\mathscr{K} \frac{\alpha p_{1} h_{1}}{y_{0}-\alpha(1+\rho) E\left[I^{*}\right]} \\
& +\sum_{\theta_{i} \in\left[\theta_{l}, \theta_{u}\right]} p_{\theta i} \int_{0}^{\infty}\left\{\mathscr{K} \frac{h_{0}-\theta_{i}}{y_{0}-(1+\rho) E\left[I^{*}\right]}+\delta \frac{h_{0}-\theta_{i}}{w_{0}-x+I^{*}}\left(-1_{\{x>d\}}\right)\right\} \mathrm{d} F\left(x \mid \Theta=\theta_{i}\right),
\end{aligned}
$$

where $\mathscr{K}=(1+\rho) \sum_{\theta_{i} \in\left[\theta_{l}, \theta_{u}\right]} p_{\theta i}\left(1-F\left(d \mid \Theta=\theta_{i}\right)\right)$. Furthermore, the optimal premium $\pi^{*}$ is $(1+\rho) E\left[I^{*}\right]$.

$$
\begin{aligned}
N= & E\left[U\left(X, \Theta, I^{*},(1+\rho) E\left[I^{*}\right]\right)\right] \\
= & p_{0} h_{0} \cdot\left(\log \left(y_{0}-(1+\rho) E\left[I^{*}\right]\right)+\delta \log \left(w_{0}\right)\right)+p_{1} h_{1} \cdot\left(\log \left(y_{0}-\alpha \cdot(1+\rho) E\left[I^{*}\right]\right)+\delta \log \left(w_{0}\right)\right) \\
& +\sum_{\theta_{i} \in\left[\theta_{l}, \theta_{u}\right]} p_{\theta i} \int_{0}^{\infty}\left(h_{0}-\theta_{i}\right) \cdot\left(\log \left(y_{0}-(1+\rho) E\left[I^{*}\right]\right)+\delta \log \left(w_{0}-x+I^{*}\right)\right) \mathrm{d} F\left(x \mid \Theta=\theta_{i}\right) .
\end{aligned}
$$

From the first-order condition that $(\partial N / \partial d)=0$, we have equation (16). Thus, we prove the proposition.

3.2. The Optimal Combinational Reinsurance. We derive the solution to the problem $\mathbf{P}_{2}$ in three steps as detailed below.

Step 1 : we derive the probability density function and mean value of the claim covered by the insurer before reinsurance arrangement $Y$.

According to the model setup, in the case that shocks to the insured's health status occur, we define the marginal distribution function of nonnegative loss $X$ as follows:

$$
f_{X}(x)= \begin{cases}1-\sum_{\theta_{i} \in\left[\theta_{l}, \theta_{u}\right]} p_{\theta i}, & x=0, \\ \sum_{\theta_{i} \in\left[\theta_{l}, \theta_{u}\right]} p_{\theta i} f\left(x \mid \Theta=\theta_{i}\right), & x>0 .\end{cases}
$$

From the optimal insurance deductible, we can define the claim covered by the insurer before reinsurance arrangement as follows:

$$
Y:=I^{*}(x)=\left(X-d^{*}\right)^{+},
$$

and determine its probability density function by

$$
f_{Y}(y)= \begin{cases}1-\sum_{\theta_{i} \in\left[\theta_{l}, \theta_{u}\right]} p_{\theta i}+\sum_{\theta_{i} \in\left[\theta_{l}, \theta_{u}\right]} p_{\theta i} F\left(d^{*} \mid \Theta=\theta_{i}\right), & y=0, \\ \sum_{\theta_{i} \in\left[\theta_{l}, \theta_{u}\right]} p_{\theta i} f\left(y+d^{*} \mid \Theta=\theta_{i}\right), & y>0 .\end{cases}
$$

Then, we can derive the mean value of $Y$ as follows:

$$
E[Y]=\sum_{\theta_{i} \in\left[\theta_{l}, \theta_{u}\right]} p_{\theta i} \int_{0}^{\infty} y f\left(y+d^{*} \mid \Theta=\theta_{i}\right) \mathrm{d} y
$$

Step 2 : in order to solve the optimization problem $\mathbf{P}_{2}$, we give the following Lemma.

The proof is similar to that in Zhou et al. [52], so we omit it and refer the reader to Section 2 of [52], for details.

Step 3 : with the help of Lemma 1, we drive the optimal proportion $a^{*}$ and the optimal retention $b^{*}$. The main results are summarized in the following Theorem.
Lemma 1. The minimal value $\operatorname{VaR}_{p}\left[a^{*} Y \wedge b^{*}\right]$ is attained on the curve of

$$
E[a Y \wedge b]=E[Y]-\frac{\beta \pi^{*}}{1+\eta}
$$

Theorem 1. If the insurer takes quota share before excess-ofloss reinsurance to minimize the VaR of its retained risk at the confidence level $p$, then

(1) For $\operatorname{VaR}_{p}[Y] \leq\left(\bar{b} E[Y] /\left(E[Y]-\left(\beta \pi^{*} /(1+\eta)\right)\right)\right)$, (or $\left.\operatorname{VaR}_{p}[Y] \leq(b / a)\right)$, where $\bar{b}$ satisfies $E[Y \wedge \bar{b}]=$ $E[Y]-\left(\beta \pi^{*} /(1+\eta)\right)$, the optimal reinsurance is pure quota share with the retention level $a^{*}=1-$ $\left(\beta \pi^{*} /(E[Y](1+\eta))\right)$. The minimal value $V a R_{p}$ $\left[a^{*} Y \wedge b^{*}\right]$ is $\left(1-\left(\beta \pi^{*} /(E[Y](1+\eta))\right)\right) \operatorname{VaR}_{p}[Y]$. 
(2) For $\operatorname{VaR}_{p}[Y] \geq\left(\bar{b} E \quad[Y] /\left(E[Y]-\left(\beta \pi^{*} /(1+\eta)\right)\right)\right)$, (or $\left.\operatorname{VaR}_{p}[Y] \geq(b / a)\right)$, the optimal reinsurance is pure excess of loss with the retention level $b^{*}=\bar{b}$. The minimal value $\operatorname{VaR}_{p}\left[a^{*} Y \wedge b^{*}\right]$ is $\bar{b}$.

Inspired by Zhou et al. [52], we give a brief proof below.

Proof. According to Lemma 1, for $\operatorname{VaR}_{p}[Y] \leq(b / a)$, $\operatorname{VaR}_{p}[a Y \wedge b]=a \operatorname{VaR}_{p}[Y]$. The minimum value is obtained at the vertical asymptote of the curve $E[a Y \wedge b]=$ $E[Y]-\left(\beta \pi^{*} /(1+\eta)\right)$, i.e., $a^{*}=1-\left(\beta \pi^{*} /(E[Y](1+\eta))\right)$. Hence, the minimal value $\operatorname{VaR}_{p}\left[a^{*} Y \wedge b^{*}\right]$ is $\left(1-\left(\beta \pi^{*} /(E[Y](1+\eta))\right)\right) \operatorname{VaR}_{p}[Y]$. According to Lemma 1 , for $\operatorname{VaR}_{p}[Y] \geq(b / a), \operatorname{VaR}_{p}[a Y \wedge b]=b^{*}=\vec{b}$ and $a^{*}=1$. Hence, the minimal value $\operatorname{VaR}_{p}\left[a^{*} Y \wedge b^{*}\right]$ is $\bar{b}$. For $\operatorname{VaR}_{p}[Y]=(b / a)$, both pure quota-share reinsurance and pure excess-of-loss reinsurance are optimal. Thus, we can conclude Theorem 1.

\section{Numerical Analysis}

In this section, we present a simple numerical example to illustrate the theoretical results obtained in the previous section. We also examine the effects of key parameters on the optimal insurance indemnity and the optimal combinational reinsurance treaty.

4.1. Simplified Model for Illustration. Our paper develops the optimal insurance-reinsurance strategy for a three-party system, i.e., "policyholder-insurer-reinsurer." In addition, we also consider the effect of health management on health insurance design. For illustration purpose, we consider three basic cases that may occur during the term of health insurance in numerical analysis, i.e., (i) the insured does not get any disease with probability $p_{0}$, (ii) the insured improves his/her health status with health management service with probability $p_{1}$, and (iii) some severe or critical illness degenerates the insured's health status after treatment with probability $p_{2}$. We assume that the loss $X$ follows exponential distribution conditional on occurrence of shocks to the insured's health status, and the density function is

$$
f(x \mid \Theta=\theta)=m e^{-m x},
$$

where $m$ is the intensity parameter. According to the theoretical solutions to the optimization problem $\mathbf{P}_{1}$ and $\mathbf{P}_{2}$, the optimal insurance indemnity is

$$
I^{*}(x)=(x-d)^{+}
$$

where the optimal deductible $d^{*}$ is determined by

$$
\begin{aligned}
0= & \mathscr{J} \frac{p_{0} h_{0}}{y_{0}-(1+\rho) E\left[I^{*}\right]}+\mathscr{J} \frac{\alpha p_{1} h_{1}}{y_{0}-\alpha(1+\rho) E\left[I^{*}\right]} \\
& +p_{2} \int_{0}^{\infty}\left\{\mathscr{J} \frac{h_{0}-\theta}{y_{0}-(1+\rho) E\left[I^{*}\right]}\right. \\
& \left.+\delta \frac{h_{0}-\theta}{w_{0}-x+I^{*}}\left(-1_{\{x>d\}}\right)\right\} \mathrm{d} F(x \mid \Theta=\theta),
\end{aligned}
$$

where $\mathscr{J}=(1+\rho) p_{2}(1-F(d \mid \Theta=\theta))$. The optimal premium $\pi^{*}$ is $(1+\rho) E\left[I^{*}\right]$. Then, we can further calculate the optimal combinational reinsurance strategy under the $\mathrm{VaR}$ optimization criterion and the reinsurance premium constraint by using Theorem 1 . The parameter values and numerical results are presented in Section 4.2.

\subsection{Numerical Results}

4.2.1. Parameter Values. We take reference of the newly released China Life Insurance Critical Illness Morbidity Table (2020 version), Chinese Family Panel Studies (CFPS) data, China Health and Nutrition Survey (CHNS) data, China Health and Retirement Longitudinal Study (CHARLS) data, and the numerical illustration in existing literatures to decide the parameter values. Throughout the numerical analysis, unless otherwise stated, the basic parameters are as given in Table 1.

Remark 3. Most of the parameters in our model, for example, disease incidence rate, health degeneration, and health status, should vary with respect to the insured's age. We assign parameter values for illustration purpose only. Therefore, we do not perform analysis over the whole life cycle. Our study provides a framework of individual-level optimal insurance indemnity design and per-loss optimal combinational reinsurance strategy.

4.2.2. The Optimal Insurance Indemnity. From Propositions 2 and 3, we obtain the optimal insurance indemnity $I^{*}(x)$ as follows:

$$
I^{*}(x)= \begin{cases}0, & 0<x<1.528 \\ x-1.528, & 1.528 \leq x<\infty\end{cases}
$$

which is shown graphically in Figure 1. The optimal health insurance premium $\pi^{*}$ is 0.1325 .

To examine the effect of key parameters on the optimal deductible, we conduct various sensitivity tests of the premium discount rate $\alpha$ and the insurance safety loading factor $\rho$. Figure 2 depicts the variation of $d^{*}$ with respect to $\alpha$. We observe that a greater $\alpha$ leads to a greater $d^{*}$, which indicates that the health insurance policy covers less medical cost as the premium discount rate approaches to 1 . Moreover, when $\alpha$ takes value 1 , the health management discounted premium offer is actually not in force and the health insurance product reduces to a traditional one. For a traditional health insurance policy, $d^{*}$ increases to 1.553 and $\pi^{*}$ decreases to 0.1299 . Figure 3 shows that $d^{*}$ increases as $\rho$ increases. Moreover, in comparison with Figure 2, we find that $d^{*}$ is more sensitive to $\rho$. From the perspective of the insured's utility, the health management service is beneficial. From the perspective of the insurer's cost management, it may be challenging to make health management service cost efficient. Therefore, the insurer should be cautious in balancing product competitiveness and product profitability when embracing "health management" in the product design. 
TABLE 1: Parameter values for the illustration model.

\begin{tabular}{lcc}
\hline Parameter & Symbol & Value \\
\hline The probability that no shock to insured's health status occurs & $p_{0}$ & 0.5 \\
The probability that the insured gets discount premium & $p_{1}$ & 0.2 \\
The probability that the insured's health status degenerates & $p_{2}$ & 0.3 \\
Insurance safety loading & $\rho$ & 0.2 \\
Reinsurance safety loading & $\theta$ & 0.3 \\
Severity of health degeneration after treatment & $h_{0}$ & 0.3 \\
Initial health status & $h_{1}$ & 0.8 \\
Improved health status & $w_{0}$ & 0.9 \\
Initial wealth & $y_{0}$ & 2 \\
Initial income & $\delta$ & 1 \\
Discount factor & $m$ & 0.9 \\
Intensity parameter & $\alpha$ & 0.8 \\
Premium discount rate & 0.8 \\
Reinsurance premium constraint & 0.8 \\
VaR confidence level & 0.99 \\
\hline
\end{tabular}

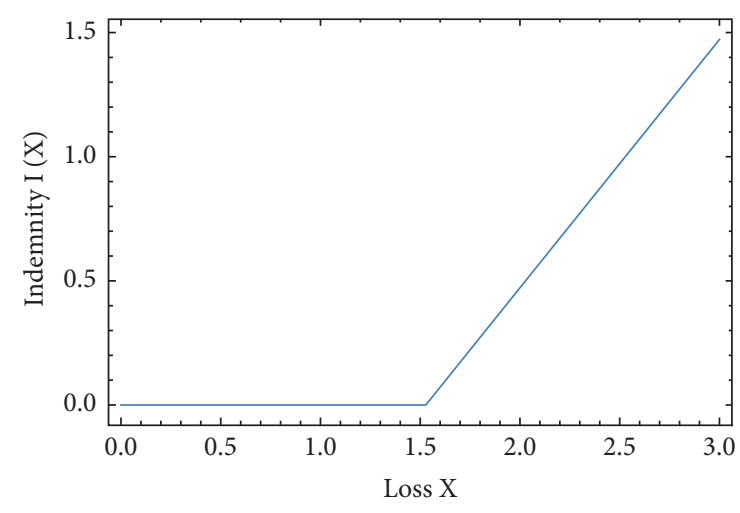

Figure 1: Optimal indemnity before reinsurance.

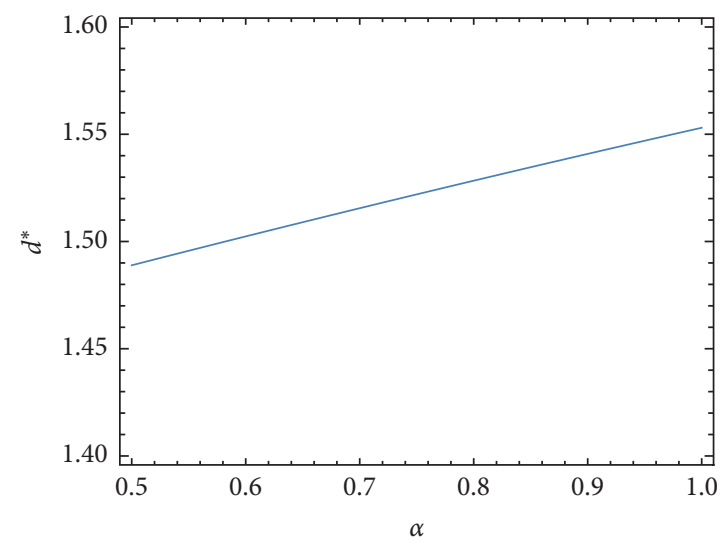

FIGURE 2: Sensitivity of $d^{*}$ with respect to the premium discount rate $\alpha$.

4.2.3. The Optimal Combinational Reinsurance Treaty. With the optimal deductible in force, the loss covered by the insured is

$$
\text { Payment by Insured }= \begin{cases}x, & 0<x<d^{*}, \\ d^{*}, & d^{*} \leq x<\infty .\end{cases}
$$

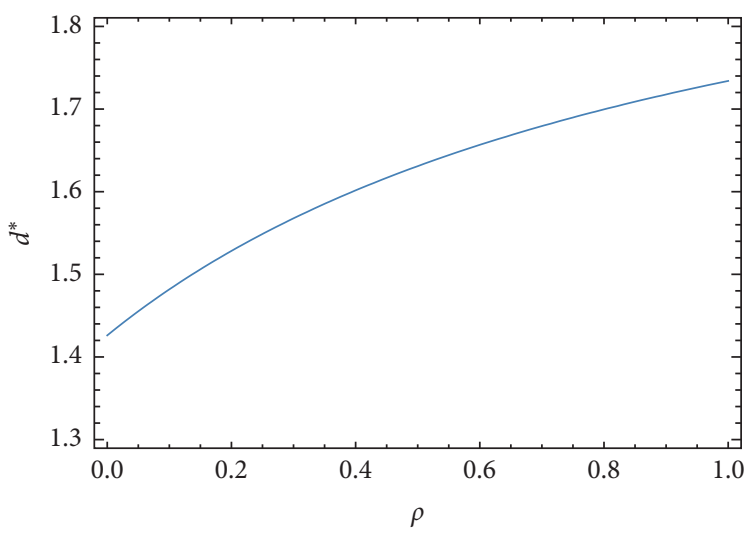

FIGURE 3: Sensitivity of $d^{*}$ with respect to the insurance safety loading factor $\rho$.

The loss covered by the insurer before reinsurance arrangement and the conditional probability density function are as follows:

$$
\begin{aligned}
Y & =I^{*}(x)=\left(X-d^{*}\right)^{+}, \\
f_{Y}(y) & = \begin{cases}1-p_{2}+p_{2} F\left(d^{*} \mid \Theta=\theta\right), & y=0, \\
p_{2} f\left(y+d^{*} \mid \Theta=\theta\right), & y>0 .\end{cases}
\end{aligned}
$$

Thus, we get $E[Y]=0.1104$ and $\bar{b}=0.3793$. With $\beta=0.8$ and $\pi^{*}=0.1325$, we can further determine the boundary curve, i.e.,

$$
E[a Y \wedge b]=E[Y]-\frac{\beta \pi^{*}}{1+\eta}=0.0289 .
$$

Since $Y$ is a mixed exponential random variable, the $\mathrm{VaR}_{p}[Y]$ values at different confidence levels $p$ are as follows:

$$
\begin{aligned}
\operatorname{VaR}_{p=0.90}[Y] & =0, \\
\operatorname{VaR}_{p=0.95}[Y] & =0.7117, \\
\operatorname{VaR}_{p=0.99}[Y] & =2.7235 .
\end{aligned}
$$




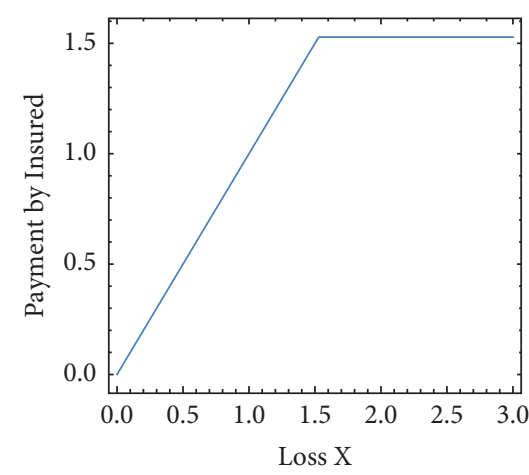

(a)

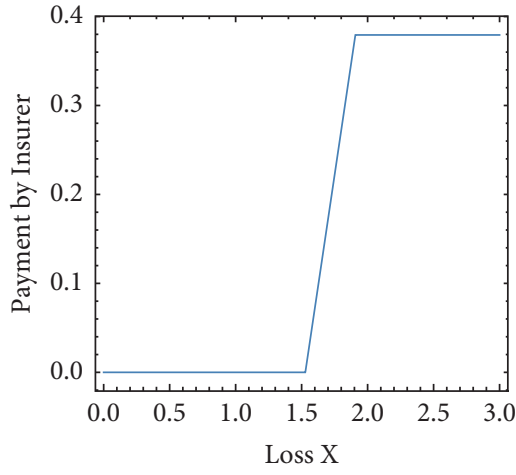

(b)

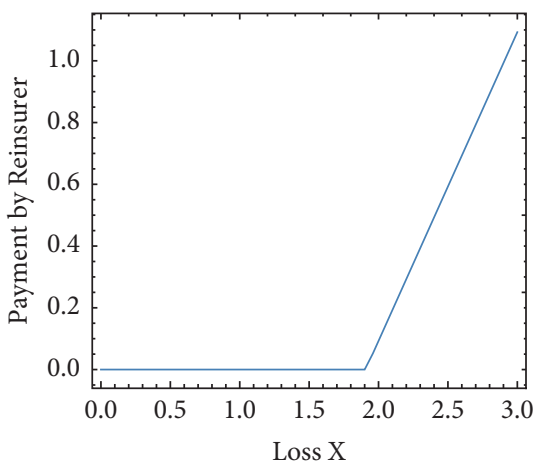

(c)

Figure 4: Optimal insurance-reinsurance (excess-of-loss) strategy. (a) Payment by the insured. (b) Payment by the insurer. (c) Payment by the reinsurer.

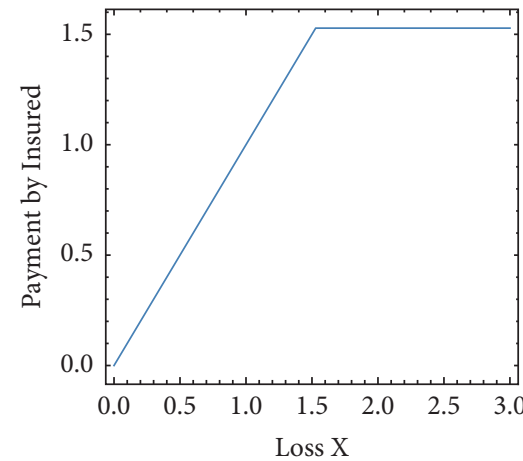

(a)

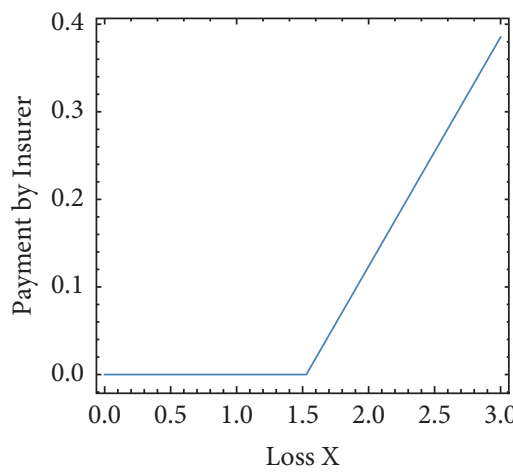

(b)

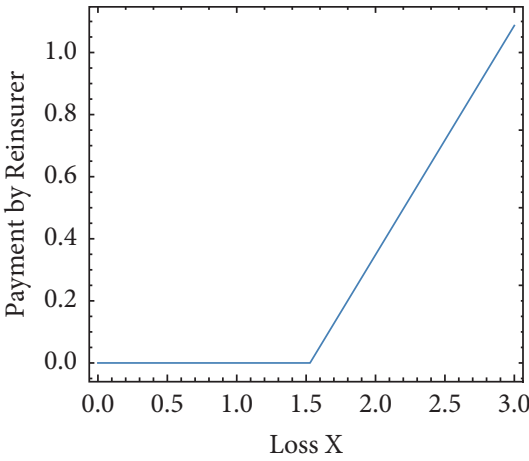

(c)

Figure 5: Optimal insurance-reinsurance (quota share) strategy. (a) Payment by the insured. (b) Payment by the insurer. (c) Payment by the reinsurer.

TABle 2: Sensitivity test results on $\eta$.

\begin{tabular}{lcccrr}
\hline$\eta$ & 0.3 & 0.4 & 0.5 & 0.6 & 0.7 \\
\hline$a^{*}$ & 0.2617 & 0.3145 & 0.3602 & 0.4002 & 0.4354 \\
$b^{*}$ & 0.3793 & 0.4719 & 0.5582 & 0.6389 & 0.7146 \\
$\left(\bar{b} E[Y] /\left(E[Y]-\left(\beta \pi^{*} /(1+\eta)\right)\right)\right)$ & 1.4492 & 1.5006 & 1.5498 & 1.5966 & 1.6411 \\
\hline
\end{tabular}

TABLE 3: Sensitivity test results on $\beta$.

\begin{tabular}{lccccc}
\hline$\beta$ & 0.5 & 0.6 & 0.7 & 0.8 & 0.9 \\
\hline$a^{*}$ & 0.5386 & 0.4463 & 0.3540 & 0.2617 & 0.1695 \\
$b^{*}$ & 0.9668 & 0.7389 & 0.5462 & 0.393 & 0.2321 \\
$\left(\bar{b} E[Y] /\left(E[Y]-\left(\beta \pi^{*} /(1+\eta)\right)\right)\right)$ & 1.7591 & 1.6556 & 1.5429 & 1.4492 & 1.3697 \\
\hline
\end{tabular}


By Theorem 1, under the confidence level $p=0.99$, the optimal reinsurance is pure excess-of-loss reinsurance with the retention level $b^{*}=\bar{b}$. The payment by the insurer and the reinsurer are as follows:

$$
\begin{gathered}
\text { Payment by Insurer }= \begin{cases}0, & 0<x<d^{*}, \\
x-d^{*}, & d^{*} \leq x<d^{*}+b^{*}, \\
b^{*}, & d^{*}+b^{*} \leq x<\infty,\end{cases} \\
\text { Payment by Reinsurer }= \begin{cases}0, & 0<x<d^{*}+b^{*}, \\
x-d^{*}-b^{*}, & d^{*}+b^{*} \leq x<\infty .\end{cases}
\end{gathered}
$$

With the deductible and excess-of-loss reinsurance in force, the loss covered by the insured, the insurer, and the reinsurer are depicted in Figure 4 . If we change the confidence level to $p=0.95$ or $p=0.90$, the optimal reinsurance is pure quota-share reinsurance with the retention level $a^{*}=0.2617$. The payment by the insurer and the reinsurer are as follows:

$$
\begin{gathered}
\text { Payment by Insurer }= \begin{cases}0, & 0<x<d^{*}, \\
a^{*}\left(x-d^{*}\right), & d^{*} \leq x<\infty,\end{cases} \\
\text { Payment by Reinsurer }= \begin{cases}0, & 0<x<d^{*}, \\
\left(1-a^{*}\right) \times\left(x-d^{*}\right), & d^{*} \leq x<\infty .\end{cases}
\end{gathered}
$$

With the deductible and quota-share reinsurance in force, the loss covered by the insured, the insurer, and the reinsurer are depicted in Figure 5. To examine the effect of key parameters on the optimal reinsurance treaty, we perform sensitivity tests on $\eta$ and $\beta$ and then summarize the results in Tables 2 and 3. We observe that (i) when the confidence level is relatively low, i.e., $p=0.90$ or $p=0.95$, the optimal reinsurance is pure quota-share reinsurance; when the confidence level is relatively high, i.e., $p=0.99$, the optimal reinsurance is pure excess-of-loss reinsurance; (ii) both $a^{*}$ and $b^{*}$ increase as $\eta$ increases; (iii) both $a^{*}$ and $b^{*}$ decreases as $\beta$ increases.

\section{Conclusion}

This paper considers optimal insurance indemnity and combinational reinsurance strategy for health insurance under the application of health management. The models and optimization problems proposed in this paper are reflection of reality and the solutions obtained herein shed light on health insurance design. Distinguished from existing literature, our study involves three parties: the insured, the insurer, and the reinsurer. The optimal deductible is derived under the optimization criterion of maximizing the insured's expected utility. The optimal quota-share and excess-of-loss reinsurance treaties are combined under the optimization criterion of minimizing the value-at-risk (VaR) of truncated loss. We also utilize the reinsurance premium as an important constraint. In addition to theoretical analysis, numerical illustrations are provided to examine the impact of various key factors on the optimal solutions.
We develop a pricing and risk management framework for health insurance with consideration of health management at the individual level. With the help of multiple optimization techniques, we obtain the analytical solutions to the corresponding optimization problems, and it leads to convenient in-depth analysis, both theoretically and numerically. This work explores that the optimal insurance is deductible and the optimal deductible increases as the premium discount rate increases; the optimal combinational reinsurance strategy heavily depends on the safety loading factor and the reinsurance premium constraint.

This work has some limitations. For example, the optimal strategies are derived under complete information and expectation premium principle. In future research, more efforts should be made to further enhance the present work. The model proposed in this paper can be extended in several directions. One is to consider the optimal insurance-reinsurance problem under partial information or ambiguity constraints, and the reliable uncertainty management could be applied to provide more useful information for health insurance design. Another direction is to investigate the optimal insurance-reinsurance problem under more general premium principles and embrace many premium principles as special cases. Besides, multiple optimization objectives and multiple constraints could be applied to formulate the optimization problem. It is also interesting to extend the research by using some interpretable machine learning tool to quantify the feature/parameter importance, for instance, random forest classification.

\section{Appendix}

\section{A. Mean-VaR Combinational Reinsurance Optimization Problem for Excess of Loss before Quota share}

Suppose that the insurer takes excess of loss before quotashare combinational reinsurance as follows:

(1) Firstly, the insurer arranges a excess-of-loss reinsurance treaty with the retention level $b, 0 \leq b<+\infty$, so that the claim covered by the insurer becomes $\min \{Y, b\}=Y \wedge b$

(2) Secondly, the insurer arranges a quota-share reinsurance treaty with the retention level $a, 0 \leq a \leq 1$, so that the claim covered by the insurer becomes $a(Y \wedge b)$

(3) As such, the claim covered by the reinsurer is $Y-a(Y \wedge b)$

(4) The insurer has to pay for reinsurance premium based on the expected value principle, i.e., $(1+\eta) E[Y-a(Y \wedge b)]$

(5) To ensure the net premium received by the insurer after reinsurance is positive, we impose the constraint $E[Y-a(Y \wedge b)] \leq\left(\beta \pi^{*} /(1+\eta)\right)$ on the reinsurance treaty

Let $\mathcal{U}$ denote the set of all admissible combinational quota-share and excess-of-loss reinsurance retentions $(a, b)$ 
which satisfy the aforementioned conditions. The insurer aims to minimize the $\mathrm{VaR}$ of the borne risk at a confidence level $p$. With $(a, b) \in \mathcal{U}$ as the decision variables, the optimal reinsurance strategy problem can be described as follows.

Problem P3:

$$
\begin{aligned}
& \operatorname{MinimizeVaR}_{p}[a(Y \wedge b)] \\
& \text { subject to } E[Y-a(Y \wedge b)] \leq \frac{\beta \pi^{*}}{1+\eta} .
\end{aligned}
$$

In order to solve the optimization problem $\mathbf{P}_{3}$, we give the following Lemma.

Lemma 2. The minimal value $\operatorname{VaR}_{p}\left[a^{*}\left(Y \wedge b^{*}\right)\right]$ is attained on the curve of

$$
E[a(Y \wedge b)]=E[Y]-\frac{\beta \pi^{*}}{1+\eta}
$$

Proof.

$$
\operatorname{VaR}_{p}[a(Y \wedge b)]=a \operatorname{VaR}_{p}[Y \wedge b] .
$$

For $\operatorname{VaR}_{p}[Y] \leq b, \quad \operatorname{VaR}_{p}[a(Y \wedge b)]=a \operatorname{VaR}_{p}[Y]$. The minimum value is attained when $a$ is minimal. For $\operatorname{VaR}_{p}[Y] \geq b, \operatorname{VaR}_{p}[a(Y \wedge b)]=a b$. The minimum value is attained at minimal $a$ and minimal $b$. Therefore, the whole minimal value $\operatorname{VaR}_{p}\left[a^{*}\left(Y \wedge b^{*}\right)\right]$ is attained on the boundary line of $E[Y-a(Y \wedge b)]=\left(\beta \pi^{*} /(1+\eta)\right)$.

With the help of Lemma 2, we drive the optimal proportion $a^{*}$ and the optimal retention $b^{*}$. We summarize the main results in the following theorem.

Theorem 2. If the insurer takes quota share after excess-ofloss reinsurance to minimize the VaR of its retained risk at the confidence level $p$, then

(1) For $\operatorname{VaR}_{p}[Y] \leq E[Y]$, the optimal reinsurance is pure quota share with the retention level $a^{*}=a_{\min }=1-$ $\left(\beta \pi^{*} / \quad(E[Y](1+\eta))\right)$. The minimal value $\operatorname{VaR}_{p}\left[a^{*}\left(Y \wedge b^{*}\right)\right] \quad$ is $\left(1-\left(\beta \pi^{*} /(E[Y](1+\eta))\right)\right)$ $\operatorname{VaR}_{p}[Y]$.

(2) For $\operatorname{VaR}_{p}[Y] \geq E[Y]$, the optimal reinsurance is pure excess-of-loss with the retention level $b^{*}=\bar{b}$ or combinational quota-share and excess-of-loss with retentions $a^{*}$ and $b^{*}$.

$\bar{b}$ satisfies $E[Y \wedge \bar{b}]=E[Y]-\left(\beta \pi^{*} /(1+\eta)\right)$. The optimal retentions $a^{*}$ and $b^{*}$ for combinational reinsurance are determined by

$$
a b=E[Y]-\frac{\beta \pi^{*}}{1+\eta}, \quad a_{\min }<a<1, \bar{b}<b<E[Y]
$$

The minimal value $\operatorname{VaR}_{p}\left[a^{*}\left(Y \wedge b^{*}\right)\right]$ is $E[Y]-\left(\beta \pi^{*} /(1+\eta)\right)$.

Proof. According to Lemma 2,

$$
E[a(Y \wedge b)]= \begin{cases}a E[Y], & E[Y] \leq b, \\ a b, & E[Y] \geq b .\end{cases}
$$

For $\quad \operatorname{VaR}_{p}[Y] \leq E[Y] \leq b, \quad$ we get $\operatorname{VaR}_{p}[a(Y \wedge b)]=a \operatorname{VaR}_{p}[Y]$. The minimum value is attained at the vertical asymptote of curve $E[a(Y \wedge b)]=E[Y]-\left(\beta \pi^{*} /(1+\eta)\right), \quad$ i.e., $a^{*}=a_{\min }=1-\left(\beta \pi^{*} /(E[Y](1+\eta))\right)$. Hence, the minimal value $\quad \operatorname{VaR}_{p}\left[a^{*}\left(Y \wedge b^{*}\right)\right]=\left(1-\left(\beta \pi^{*} /(E[Y](1+\eta))\right)\right)$ $\operatorname{VaR}_{p}[Y]$.

For $\operatorname{VaR}_{p}[Y] \geq E[Y]>b$, we get $\operatorname{VaR}_{p}[a(Y \wedge b)]=a b=$ $E[Y]-\left(\beta \pi^{*} /(1+\eta)\right)$. The minimum value is attained at $a^{*}=1$ and $b^{*}=\bar{b}$ which lead to pure excess-of-loss reinsurance, or the boundary curve $a b=E[Y]-\left(\beta \pi^{*} /(1+\eta)\right)$, $a_{\min }<a<1, \bar{b}<b<E[Y]$, which lead to combinational reinsurance.

Thus, we can conclude Theorem 2 .

\section{Data Availability}

The data used to support the findings of this study are available from the corresponding author upon request.

\section{Conflicts of Interest}

The author declares that there are no conflicts of interest regarding the publication of this paper.

\section{Acknowledgments}

This research work was supported by the National Natural Science Foundation of China (nos. 12001119, 72071051, and 71871071), the Key Program of the National Social Science Foundation of China (no. 21AZD071), and the Guangdong Basic and Applied Basic Research Foundation (no. 2018B030311004).

\section{References}

[1] K. J. Arrow, "Uncertainty and the welfare economics of medical care," The American Economic Review, vol. 53, pp. 941-973, 1963.

[2] K. J. Arrow, Essays in the Theory of Risk Bearing, Markham, Chicago, IL, USA, 1971.

[3] K. J. Arrow, "Optimal insurance and generalized deductibles," Scandinavian Actuarial Journal, vol. 1974, no. 1, pp. 1-42, 1974.

[4] V. L. Smith, "Optimal insurance coverage," Journal of Political Economy, vol. 76, no. 1, pp. 68-77, 1968.

[5] M. Spence and R. Zeckhauser, "Insurance, information, and individual action," The American Economic Review, vol. 61, pp. 380-387, 1971.

[6] A. Raviv, "The design of an optimal insurance policy," The American Economic Review, vol. 69, pp. 84-96, 1979.

[7] C. Gollier and H. Schlesinger, "Arrow's theorem on the optimality of deductibles: a stochastic dominance approach," Economic Theory, vol. 7, no. 2, pp. 359-363, 1996.

[8] V. R. Young, "Optimal insurance under Wang's premium principle," Insurance: Mathematics and Economics, vol. 25, no. 2, pp. 109-122, 1999. 
[9] C.-P. Wang, D. Shyu, and H.-H. Huang, "Optimal insurance design under a value-at-risk framework," The Geneva Risk and Insurance Review, vol. 30, no. 2, pp. 161-179, 2005.

[10] S. D. Promislow and V. R. Young, "Unifying framework for optimal insurance," Insurance: Mathematics and Economics, vol. 36, no. 3, pp. 347-364, 2005.

[11] K. S. Moore and V. R. Young, "Optimal insurance in a continuous-time model," Insurance: Mathematics and Economics, vol. 39, no. 1, pp. 47-68, 2006.

[12] K. Lee, "Wealth, income, and optimal insurance," Journal of Risk \& Insurance, vol. 74, no. 1, pp. 175-184, 2007.

[13] C. Zhou and C. Wu, "Optimal insurance under the insurer's risk constraint," Insurance: Mathematics and Economics, vol. 42, no. 3, pp. 992-999, 2008.

[14] C. Zhou, W. Wu, and C. Wu, "Optimal insurance in the presence of insurer's loss limit," Insurance: Mathematics and Economics, vol. 46, no. 2, pp. 300-307, 2010.

[15] C. Bernard, X. He, J.-A. Yan, and X. Y. Zhou, "Optimal insurance design under rank-dependent expected utility," Mathematical Finance, vol. 25, no. 1, pp. 154-186, 2015.

[16] Z. Q. Xu, X. Y. Zhou, and S. C. Zhuang, "Optimal insurance under rank-dependent utility and incentive compatibility," Mathematical Finance, vol. 29, no. 2, pp. 659-692, 2019.

[17] B. K. Sarkar and S. S. Sana, "An e-healthcare system for disease prediction using hybrid data mining technique," Journal of Modelling in Management, vol. 14, no. 3, pp. 628-661, 2019.

[18] B. K. Sarkar and S. S. Sana, "A conceptual distributed framework for improved and secured healthcare system," International Journal of Healthcare Management, vol. 13, no. 1, pp. 74-87, 2018.

[19] N. M. Modak, S. Panda, and S. S. Sana, "Optimal inventory policy in hospitals: a supply chain model," Revista de la Real Academia de Ciencias Exactas, Fisicas y Naturales. Serie A, Matehmaticas, vol. 114, no. 3, 2020.

[20] A. Moheimani, R. Sheikh, S. M. H. Hosseini, and S. S. Sana, "Assessing the preparedness of hospitals facing disasters using the rough set theory: guidelines for more preparedness to cope with the COVID-19," International Journal of Systems Science: Operations \& Logistics, vol. 11, pp. 1-16, 2021.

[21] A. Moheimani, R. Sheikh, S. M. H. Hosseini, and S. S. Sana, "Assessing the agility of hospitals in disaster management: application of interval type-2 fuzzy flowsort inference system," Soft Computing, vol. 25, no. 5, pp. 3955-3974, 2021.

[22] T. J. Besley, "Optimal reimbursement health insurance and the theory of Ramsey taxation," Journal of Health Economics, vol. 7, no. 4, pp. 321-336, 1988.

[23] R. P. Ellis, S. Jiang, and W. G. Manning, "Optimal health insurance for multiple goods and time periods," Journal of Health Economics, vol. 41, pp. 89-106, 2015.

[24] S. Bhargava, G. Loewenstein, and J. Sydnor, "Choose to lose: health plan choices from a menu with dominated option," Quarterly Journal of Economics, vol. 132, no. 3, pp. 1319-1372, 2017.

[25] D. Doiron and N. Kettlewell, "Family formation and the demand for health insurance," Health Economics, vol. 29, no. 4, pp. 523-533, 2020.

[26] W. K. Viscussi and W. N. Evans, "Utility functions that depend on health status: estimates and economic implications," The American Economic Review, vol. 80, pp. 353-374, 1990.

[27] Å. Blomqvist, "Optimal non-linear health insurance," Journal of Health Economics, vol. 16, no. 3, pp. 303-321, 1997.

[28] R. E. Hall and C. I. Jones, "The value of life and the rise in health spending," Quarterly Journal of Economics, vol. 122, no. 1, pp. 39-72, 2007.
[29] A. Finkelstein, E. F. P. Luttmer, and M. J. Notowidigdo, "What good is wealth without health? The effect of health on the marginal utility of consumption," Journal of the European Economic Association, vol. 11, pp. 221-258, 2013.

[30] Y. Zhang and Y. Wu, "Optimal health insurance and trade-off between health and wealth," Journal of Applied Mathematics, vol. 2020, Article ID 2658213, 9 pages, 2020.

[31] M. Levy and A. R. Nir, "The utility of health and wealth," Journal of Health Economics, vol. 31, no. 2, pp. 379-392, 2012.

[32] J. S. Pliskin, D. S. Shepard, and M. C. Weinstein, "Utility functions for life years and health status," Operations Research, vol. 28, pp. 206-224, 2016.

[33] Y. Zhang, Y. Wu, and H. Yao, "Optimal health insurance with constraints under utility of health, wealth and income," Journal of Industrial and Management Optimization, 2021.

[34] J. Cai and K. S. Tan, "Optimal retention for a stop-loss reinsurance under the VaR and CTE risk measures," Astin Bulletin, vol. 37, no. 1, pp. 93-112, 2007.

[35] K. S. Tan, C. Weng, and Y. Zhang, "VAR and CTE criteria for optimal quota-share and stop-loss reinsurance," North American Actuarial Journal, vol. 13, no. 4, pp. 459-482, 2009.

[36] C. Yusong and X. Jin, "Proportional and excess-of-loss reinsurance under investment gains," Applied Mathematics and Computation, vol. 217, pp. 256-2550, 2010.

[37] Y. C. Chi and K. S. Tan, "Optimal reinsurance under VaR and CVaR risk measures: a simplified approach," Astin Bulletin, vol. 41, pp. 547-574, 2011.

[38] J. Cai, Y. Fang, Z. Li, and G. E. Willmot, "Optimal reciprocal reinsurance treaties under the joint survival probability and the joint profitable probability," Journal of Risk \& Insurance, vol. 80, no. 1, pp. 145-168, 2012.

[39] J. Cai, C. Lemieux, and F. Liu, "Optimal reinsurance from the perspectives of both an insurer and a reinsurer," Astin Bulletin, vol. 46, no. 3, pp. 815-849, 2015.

[40] N. Zhang, Z. Jin, S. Li, and P. Chen, "Optimal reinsurance under dynamic VaR constraint," Insurance: Mathematics and Economics, vol. 71, pp. 232-243, 2016.

[41] X. Liang and V. R. Young, "Minimizing the probability of ruin: optimal per-loss reinsurance," Insurance: Mathematics and Economics, vol. 82, pp. 181-190, 2018.

[42] X. Han, Z. Liang, and V. R. Young, "Optimal reinsurance to minimize the probability of drawdown under the meanvariance premium principle," Scandinavian Actuarial Journal, vol. 2020, no. 10, pp. 879-903, 2020.

[43] Y. Fang, G. Cheng, and Z. Qu, "Optimal reinsurance for both an insurer and a reinsurer under general premium principles," AIMS Mathematics, vol. 5, no. 4, pp. 3231-3255, 2020.

[44] X. Zhang, M. Zhou, and J. Guo, "Optimal combinational quota-share and excess-of-loss reinsurance policies in a dynamic setting," Applied Stochastic Models in Business and Industry, vol. 23, no. 1, pp. 63-71, 2007.

[45] Z. Liang and J. Guo, "Optimal combining quota-share and excess of loss reinsurance to maximize the expected utility," Journal of Applied Mathematics and Computing, vol. 36, no. 12, pp. 11-25, 2011.

[46] Y. Fang and Z. Qu, "Optimal combination of quota-share and stop-loss reinsurance treaties under the joint survival probability," IMA Journal of Management Mathematics, vol. 25, no. 1, pp. 89-103, 2014.

[47] X. Hu, B. Duan, and L. Zhang, "De Vylder approximation to the optimal retention for a combination of quota-share and excess-of-loss reinsurance with partial information," Insurance: Mathematics and Economics, vol. 76, pp. 48-55, 2017. 
[48] P. Yang, Z. Chen, and L. Wang, "Time-consistent reinsurance and investment strategy combining quota-share and excess of loss for mean-variance insurers with jump-diffusion price process," Communications in Statistics - Theory and Methods, vol. 50, no. 11, pp. 2546-2568, 2019.

[49] K. Christian, "Dividend maximization under a set ruin probability target in the presence of proportional and excessof-loss reinsurance," Applications and Applied Mathematics, vol. 15, pp. 13-37, 2020.

[50] T. G. Mcguire, S. Schillo, and R. C. Van Kleef, "Reinsurance, repayments, and risk adjustment in individual health insurance," American Journal of Health Economics, vol. 6, no. 1, pp. 139-168, 2020.

[51] P. Artzner, F. Delbaen, J.-M. Eber, and D. Heath, "Coherent measures of risk," Mathematical Finance, vol. 9, no. 3, pp. 203-228, 1999.

[52] M. Zhou, H. Dong, and J. Xu, "Optimal combinational of quota-share and stop-loss reinsurance contracts under VaR and CTE with a constrained reinsurance premium," Journal of Systems Science and Complexity, vol. 24, no. 1, pp. 156-166, 2011. 